\title{
A mixed diet supplemented with L-arabinose does not alter glycaemic or insulinaemic responses in healthy human subjects
}

\author{
Kia Halschou-Jensen ${ }^{1,2 *}$, Knud E. Bach Knudsen ${ }^{3}$, Søren Nielsen ${ }^{4}$, Klaus Bukhave ${ }^{2}$ and \\ Jens R. Andersen ${ }^{2}$ \\ ${ }^{1}$ Department of Nursing, Faculty of Health and Technology, Metropolitan University Collage, Tagensvej 86, \\ DK-2200 Copenhagen, NV, Denmark \\ ${ }^{2}$ Department of Nutrition, Exercise and Sports, University of Copenhagen, Rolighedsvej 26, \\ DK-1958 Frederiksberg C, Denmark \\ ${ }^{3}$ Department of Animal Science, Aarbus University, Blichers Allé 20, DK-8830 Tjele, Denmark \\ ${ }^{4}$ Department of Endocrinology, Aarbus University Hospital, Wilhelm Meyers Allé 3, DK-800O Aarhus C, Denmark \\ (Submitted 2 January 2014 - Final revision received 20 August 2014 - Accepted 1 October 2014 - First published online 17 November 2014)
}

\begin{abstract}
In addition to a yet-to-be published study showing arabinose to have an inhibiting effect on maltase, in vitro studies have shown L-arabinose to exert an inhibiting effect on small-intestinal sucrase and maltase and the consumption of a sucrose-rich drink containing L-arabinose to exert positive effects on postprandial blood glucose, insulin and C-peptide responses in humans. However, the effects of adding L-arabinose to mixed meals on the indices of glucose control are unknown. The purpose of the present study was to investigate whether the positive effects of L-arabinose added to a sugar drink could be reproduced in subjects consuming a mixed meal containing sucrose and/or starch from wheat flour. A total of seventeen healthy men participated in study 1, a randomised, double-blind, cross-over trial. In this study, the subjects consumed two different breakfast meals containing sucrose and starch from wheat flour (meal A) or starch from wheat flour (meal B) supplemented with 0,5 and $10 \%$ L-arabinose by weight after a $12 \mathrm{~h}$ fast. A total of six healthy men participated in study 2 , a randomised, double-blind, cross-over trial. In this study, the subjects also consumed meal B served in two different textures and a liquid meal with maltose supplemented with 0 and $20 \% \mathrm{~L}$-arabinose. In addition, $1.5 \mathrm{~g}$ of paracetamol was chosen as an indirect marker to assess gastric emptying. Postprandial plasma glucose, insulin and C-peptide concentrations were measured regularly for $3 \mathrm{~h}$. The results of the present study showed that the peak plasma concentration, time to reach peak plasma concentration or AUC values of glucose, insulin and C-peptide were not altered after consumption of the test meals. Overall, it was not possible to reproduce the beneficial effects of L-arabinose added to sucrose drinks when L-arabinose was mixed in a solid or semi-solid mixed meal.
\end{abstract}

Key words: Sucrose: Maltose: L-Arabinose: Glucose: Insulin: C-peptide: Gastric emptying

The number of people with type 2 diabetes (T2D) may reach 552 million within the next 25 years ${ }^{(1,2)}$. No simple or unique cure has been documented for this major health problem and the risk factors related to this disease. Therefore, there is an urgent need for preventative measures and effective approaches to overcome this serious health issue.

This may require a combination of several interventions. Currently, the strategy for treating T2D is primarily focused on changing lifestyle, e.g. increasing physical activity and making changes to the diet, which is identical to the strategy for treating insulin resistance, impaired glucose tolerance and obesity. Furthermore, a variety of medicines are used.
The regulation of blood glucose concentrations is the major focus of $\mathrm{T} 2 \mathrm{D}$ research as even a moderate increase in postprandial glucose responses increases the risk of developing T2D and is an independent risk factor for the development of at least macrovascular complications in patients with diabetes mellitus ${ }^{(3-5)}$. One of the ways to regulate blood glucose and insulin secretion is to control the intake of food components that have a large effect on blood glucose concentrations. This especially includes decreasing the intake of starch and sugar, which can be a challenge in industrialised countries such as Denmark, where the overall intake of starch and sugar is high $^{(6)}$.

Abbreviations: $C_{\max }$, peak plasma concentration; GER, gastric emptying rate; iAOC, incremental area above the curve; iAUC, incremental AUC; T2D, type 2 diabetes; $T_{\max }$, time to reach peak plasma concentration.

*Corresponding author: K. Halschou-Jensen, fax +45 35332483, email kiahalschou@gmail.com 
One of the ways to decrease postprandial hyperglycaemia is to modulate the absorption of glucose from digested carbohydrates. Increasingly, research has focused on substances inhibiting carbohydrate digestive enzymes ${ }^{(7-9)}$ and thereby delaying absorption. Pentoses such as L-arabinose have been of interest as disaccharidase inhibitors, and several studies in rats and pigs have demonstrated a reduction in postprandial glucose ${ }^{(9)}$ and insulin responses ${ }^{(9,10)}$ following ingestion of sucrose in combination with different concentrations of L-arabinose. A study using sucrose-rich diets supplemented with L-arabinose carried out in both healthy subjects and T2D patients has demonstrated a decreased glucose response after consumption of diets supplemented with 3 and $4 \%$ L-arabinose ${ }^{(11)}$. Another study has demonstrated that L-arabinose added to a sucrose-rich drink has a lowering effect on postprandial blood glucose, insulin and C-peptide concentrations and that the mechanism underlying this effect is probably non-competitive inhibition of the brush border enzyme sucrase ${ }^{(12)}$. The use of higher dietary doses of sucrose, however, would be unfeasible in terms of palatability and would have limited clinical applicability as very few people consume sucrose at quantities of $75 \mathrm{~g}$ in one drink, as has been used in the above-mentioned study. Of greater importance would be the combination of L-arabinose with starch, as starch is the main glucose-providing carbohydrate in the diet.

A recently performed in vitro study using L-arabinose and D-xylose has demonstrated an inhibiting effect on maltase (I Krog-Mikkelsen, S Petersen, K Halschou-Jensen, O Hels, I Tetens, JJ Holst, JR Andersen and K Bukhave, unpublished results). Maltase is a disaccharidase that is important for the breakdown of starch and is present in the brush border. The data indicated that L-arabinose might have a lowering effect on blood glucose and insulin concentrations after the intake of not only sucrose but also starch.

For public health purposes, lowering effects on blood glucose and insulin concentrations would be expected if blood glucose-lowering components could be incorporated in the habitual and/or recommended diet for the majority of the population.

We hypothesised that responses similar to the positive glucose and insulin responses in human subjects following ingestion of sucrose drinks supplemented with L-arabinose would occur in subjects who consume a mixed-meal diet containing sucrose and/or starch supplemented with L-arabinose. This hypothesis was tested in the present study. Furthermore, the possible inhibiting effects of L-arabinose on maltase were investigated separately.

\section{Experimental methods}

\section{Subjects}

Study 1. A total of seventeen healthy males with normal fasting blood glucose concentrations were recruited for this study.

The inclusion criteria were as follows: healthy male; age between 18 and 30 years; normal weight (BMI $18-25 \mathrm{~kg} / \mathrm{m}^{2}$ ); waist circumference $<94 \mathrm{~cm}$ ( $>94 \mathrm{~cm}$ defined as abnormal for European men); no use of dietary supplements or regular use of medicine; not elite athlete; no changes in physical activity during the study period; no blood donation 3 months before study entry, no smoking; no alcohol intake $>21$ units of alcohol/ week. The baseline characteristics of the subjects were as follows: age 22.5 (SD 2.6) years; BMI 22 (SD 1.22) kg/m² ; blood pressure 131/71 (SD 12/8); pulse 68 (SD 12).

Study 2. A total of six healthy males were recruited for this study. The inclusion criteria were exactly the same as those of study 1 . The baseline characteristics of the subjects were as follows: age 23.3 (SD 2.9) years; BMI 22.4 (SD 1.4) kg/m² blood pressure 127/70 (SD 12/4); pulse 60 (SD 6).

\section{Design}

Study 1. This study was designed as a double-blind, controlled six-way cross-over design intervention trial and consisted of six test days of approximately $5 \mathrm{~h}$ duration. The subjects were served two different meals supplemented with three different concentrations of L-arabinose. Each test day was separated by a 1-week washout period. The subjects were instructed to refrain from consuming alcohol and performing intense physical activity $24 \mathrm{~h}$ before each test day and to fast from 20.00 hours the evening before the test day and allowed to drink only 0.5 litres of water during the fasting period. The subjects were instructed to avoid physical stress on the morning of each test day and to maintain their habitual diet and other lifestyle habits throughout the study period.

Study 2. To explore possible reasons for the findings from study 1 , a smaller study was designed with focus on starch and the possible inhibition of maltase in the intestine. This study was designed as a double-blind, controlled six-way crossover intervention trial and consisted of six test days of approximately $5 \mathrm{~h}$ duration. Each test day was separated by a minimum washout period of $48 \mathrm{~h}$. To assess variations in gastric emptying, the subjects were served three different meals varying from liquid to solid with 0 or $20 \%$ of L-arabinose. In addition, paracetamol was chosen as an indirect marker to assess gastric emptying. Paracetamol is poorly absorbed in the stomach, but rapidly absorbed in the small intestine and quantified in the blood ${ }^{(13)}$. The subjects were instructed to behave exactly as in study 1 during the study period.

Both studies were conducted according to the guidelines laid down in the Declaration of Helsinki, and all procedures involving human subjects were approved by the Ethics Committee of the Region of Copenhagen. Written informed consent was obtained from all subjects. The protocols for the postprandial study were registered at ClinicalTrials.gov (ID: NCT00302302). The studies were carried out at the Department of Nutrition, Exercise and Sports, University of Copenhagen.

\section{Meal designs}

\section{Study 1}

Test meal A. Meal A contained $2 \mathrm{MJ}$ in total, divided into $8.4 \%$ of energy as protein, $34.2 \%$ of energy as fat and $57 \cdot 4 \%$ of energy as carbohydrate. This meal consisted of a bun and a muffin containing starch and sucrose from 
Table 1. Ingredients of buns used in meals A and B

\begin{tabular}{lrrrcc}
\hline Ingredients* & \multicolumn{1}{c}{ g } & $\begin{array}{c}\text { Weight } \\
\%\end{array}$ & $\begin{array}{c}\text { Starch } \\
(\%)\end{array}$ & $\begin{array}{c}\text { Sucrose } \\
(\%)\end{array}$ & $\begin{array}{c}\text { Starch }+ \\
\text { sucrose (\%) }\end{array}$ \\
\hline Water & 1000 & 29.94 & & & \\
Yeast & 80 & 2.40 & & & \\
Yellow baking & 100 & 2.99 & & 0.99 & \\
$\quad$ syrupt & & & & & \\
Fibrex 595 & 30 & 0.90 & & & \\
Margarine & 200 & 5.99 & & & \\
Milk powder & 100 & 2.99 & & & \\
Salt & 30 & 0.90 & & 0.22 & \\
Wheat flour & 1800 & 53.89 & 36.43 & 1.20 & 37.63 \\
Total & 3340 & 100 & 36.43 & 1.20 & \\
\hline
\end{tabular}

*Weight $70 \mathrm{~g} / \mathrm{bun}$.

$+33 \%$ sucrose.

$\ddagger 67.6 \%$ starch, $0.4 \%$ sucrose and $2.5 \%$ fibre.

wheat flour supplemented with 0,5 or $10 \%$ L-arabinose by weight, $10 \mathrm{~g}$ of raspberry jam supplemented with 0,5 or $10 \%$ arabinose, $10 \mathrm{~g}$ of butter, tea of universal herbs and $300 \mathrm{ml}$ of water. The amount of L-arabinose in this meal corresponded to $0,2.9$ or $5.9 \mathrm{~g}$.

Test meal $B$. Meal B contained $2 \cdot 1 \mathrm{MJ}$ in total, divided into $13.5 \%$ of energy as protein, $29 \cdot 1 \%$ of energy as fat and $57 \cdot 4 \%$ of energy as carbohydrate. This meal consisted of two buns containing starch from wheat flour supplemented with 0,5 or $10 \% \mathrm{~L}$-arabinose by weight, $20 \mathrm{~g}$ of cheese, $10 \mathrm{~g}$ of butter, tea of universal herbs and $300 \mathrm{ml}$ of water. The amount of $\mathrm{L}$-arabinose in this meal corresponded to $0,2.5$ or $4.9 \mathrm{~g}$.

\section{Study 2}

Solid test meal. The solid meal contained $2 \cdot 1 \mathrm{MJ}$ in total, divided into $13.5 \%$ of energy as protein, $29 \cdot 1 \%$ of energy as fat and $57.4 \%$ of energy as carbohydrate. This meal consisted of two buns containing starch from wheat flour supplemented with 0 or $20 \%$ L-arabinose by weight, $20 \mathrm{~g}$ of cheese, $10 \mathrm{~g}$ of butter, $100 \mathrm{ml}$ of tea of universal herbs and $300 \mathrm{ml}$ of water. The amount of arabinose in this meal corresponded to 0 or $10 \cdot 2 \mathrm{~g}$.

Semi-solid test meal. The semi-solid meal contained $2 \cdot 1 \mathrm{MJ}$ in total, divided into $13.5 \%$ of energy as protein, $29 \cdot 1 \%$ of energy as fat and $57 \cdot 4 \%$ of energy as carbohydrate. This meal consisted of two buns containing starch from wheat flour supplemented with 0 or $20 \%$ L-arabinose by weight, $20 \mathrm{~g}$ of cheese, $10 \mathrm{~g}$ of butter, $100 \mathrm{ml}$ of tea of universal herbs and $300 \mathrm{ml}$ of water.

The solids were blended with $150 \mathrm{ml}$ of water and served as porridge. The remaining $50 \mathrm{ml}$ of water was served as a drink together with the tea. The amount of arabinose in this meal corresponded to 0 or $10 \cdot 2 \mathrm{~g}$.

Liquid test meal. The liquid meal contained $75 \mathrm{~g}$ of maltose in $300 \mathrm{ml}$ of water with and without $20 \% \mathrm{~L}$-arabinose (corresponding to $15 \mathrm{~g}$ of $\mathrm{L}$-arabinose in the meal).

\section{Test products}

Buns and muffins with 0, 5, 10 and 20\% arabinose were baked at the bakery Nordic Sugar A/S in Arløv, Sweden. Arabinose was added on a weight $\%$ basis in relation to starch and sucrose contents. L-Arabinose was purchased from Danisco A/S.

The ingredients of buns and muffins are listed in Tables 1 and 2 , respectively.

To determine the amount of arabinose in the test meals, the buns and muffins were analysed after baking to determine the arabinose content. The analyses were carried out at the Department of Animal Science, University of Aarhus, Denmark.

Arabinose content in the buns and muffins was determined using two different methods. Arabinose content in the buns was determined by direct hydrolysis - homogenisation with $12 \mathrm{M}-\mathrm{H}_{2} \mathrm{SO}_{4}$ followed by hydrolysis with $2 \mathrm{M}-\mathrm{H}_{2} \mathrm{SO}_{4}^{(14)}$. Arabinose content in the muffins was determined by direct hydrolysis after removal of lipids by extraction with diethyl ether. Arabinose in the extracts or hydrolysates was reduced with potassium borohydride to the corresponding sugar alcohol, which was acetylated with acetic anhydride using N-methyl imidazole as a catalyst ${ }^{(15)}$ before gas chromatographic analysis. The DM content in the dough, buns and muffins was determined by freeze-drying. The recovery of L-arabinose that was added was estimated to be 89 (SEM 7.6)\% for the buns and 73 (SEM 4.0)\% for the muffins. L-arabinose recovery data are given in Table 3 .

\section{Measurements}

\section{Study 1}

On each test day, the subjects were weighed to the nearest $0.05 \mathrm{~kg}$ on a digital scale (Lindeltronic 8000; Lindells). A venflon catheter was inserted into the antecubital vein and the subjects were asked to rest for $10 \mathrm{~min}$ before collecting the baseline blood samples to measure glucose, insulin and C-peptide concentrations. Fasting blood samples were collected at $-15 \mathrm{~min}$ and again at $0 \mathrm{~min}$ to ensure proper baseline values. The test meal was served immediately after collecting the blood sample at $0 \mathrm{~min}$ and was consumed within $10 \mathrm{~min}$ by the subjects. Further blood samples were drawn at 15, 30, 45, 60, 75, 90, 105, 120 and $180 \mathrm{~min}$ after consumption of the test meal. The subjects were instructed to rest and were not allowed to sleep during the postprandial period.

Table 2. Ingredients of muffins used in meal A

\begin{tabular}{|c|c|c|c|c|c|}
\hline Ingredients* & $g$ & $\begin{array}{c}\text { Weight } \\
\%\end{array}$ & $\begin{array}{l}\text { Starch } \\
(\%)\end{array}$ & $\begin{array}{l}\text { Sucrose } \\
(\%)\end{array}$ & $\begin{array}{c}\text { Starch }+ \\
\text { sucrose (\%) }\end{array}$ \\
\hline Margarine & 1000 & $14 \cdot 29$ & & & \\
\hline Milk & 850 & $12 \cdot 14$ & & & \\
\hline Sugar & 2200 & 31.43 & & 31.43 & \\
\hline Egg & 1000 & 14.29 & & & \\
\hline Wheat flour† & 1600 & $22 \cdot 86$ & $15 \cdot 45$ & 0.09 & \\
\hline Baking powderł & 50 & 0.71 & 0.29 & & \\
\hline $\begin{array}{l}\text { Crème powder } \\
\text { including vanilla§ }\end{array}$ & 300 & 4.29 & 3.69 & & \\
\hline Total & 7000 & 100 & $19 \cdot 42$ & 31.52 & $50 \cdot 94$ \\
\hline
\end{tabular}

*Weight $50 \mathrm{~g} /$ muffin.

† $67.6 \%$ starch, $0.4 \%$ sucrose and $2.5 \%$ fibre.

$\ddagger 40 \%$ starch.

$\S 86 \%$ starch. 
Table 3. Recovery of L-arabinose in the buns and muffins used in meals $A$ and $B$

\begin{tabular}{llcccc}
\hline Samples & DM (\%) & $\begin{array}{c}\text { Added } \\
\text { L-arabinose }(g)\end{array}$ & $\begin{array}{c}\text { Added arabinose }(\mathrm{g}) \\
\text { corrected for DM }\end{array}$ & $\begin{array}{c}\text { Arabinose } \\
\text { recovered }(\mathrm{g})\end{array}$ & Recovery (\%) \\
\hline Bun 5\% & 68.395 & 1.79 & 2.62 & 2.45 & 93.5 \\
Bun 10\% & 70.275 & 3.52 & 5.01 & 4.75 & 94.8 \\
Bun 20\% & 68.55 & 8.1 & 9.9 & 9.1 & 81 \\
Muffin 5\% & 83.34 & 2.48 & 2.97 & 2.1 & 70.7 \\
Muffin 10\% & 82.31 & 4.85 & 5.89 & 4.5 & 76.4 \\
\hline
\end{tabular}

\section{Study 2}

The same programme followed in study 1 was repeated in study 2 . In addition, the subjects were served $1.5 \mathrm{~g}$ of paracetamol dissolved in $50 \mathrm{ml}$ of water together with the test meal immediately after collecting the blood sample at 0 min and asked to consume the meal within $10 \mathrm{~min}$. They were instructed to mix the meal and the dissolved paracetamol. The following parameters were used for determining the rate of paracetamol absorption: peak plasma concentration $\left(C_{\max }\right)$; the time to reach $C_{\max }\left(T_{\max }\right)$; the AUC; the slope for the three different meals.

\section{Post-study measurements}

On each test day, the following gastrointestinal side effects were recorded for the following $24 \mathrm{~h}$ with questionnaires using a fivelevel scale: heartburn; distension; nausea; vomiting; stomach ache and rumbling in the gut; flatulence; diarrhoea.

\section{Laboratory analysis}

Blood glucose concentrations were determined using an enzymatic colorimetric method on an ABX Pentra analyser (HORIBA ABX). Insulin and C-peptide concentrations were measured using a chemiluminescent immunometric assay (Immulite 1000; Diagnostic Products). Paracetamol concentrations were determined using an enzyme-specific reaction method on a Horiba ABX Pentra 400 analyser (HORIBA ABX).

\section{Statistical analyses and calculations}

The incremental AUC (iAUC) or incremental area above the curve (iAOC), ignoring the area beneath (or above in the case of iAOC), for fasting concentrations was calculated geometrically by applying the trapezoidal rule. The iAUC or the iAOC was calculated for the entire test period for 0-180 min. Postprandial response curves were evaluated by comparing $C_{\max }$ values and iAUC values using ANCOVA with fasting values as covariates and $T_{\max }$ values using ANOVA. A repeated-measures ANOVA was used to examine the effect of meal and time on the postprandial response curves. Data were controlled for homogeneity of variance, which was verified by residual plots, and assumption of normal distribution was investigated using normal probability plots and histogram plots. Significant results were analysed using the TukeyKramer test for post hoc analysis. All data are presented as means with their standard errors, unless otherwise indicated, and the statistical significance level was defined as $P<0.05$.
All statistical analyses and calculations were performed using the Statistical Analysis System software package, version 9.2 (SAS Institute, Inc.).

Power calculations were based on a standard formula using variance data from a previous study with $\mathrm{L}$-arabinose added to a sugar drink $^{(12)}$.

A sample size of twenty-seven subjects was considered to be sufficient to detect a difference of $60 \mathrm{pmol} / 1$ in the concentration of C-peptide, with a power of $80 \%$ and $\alpha=0.05$. As the study had a paired design, the sample size was reduced to seventeen subjects.

\section{Results and discussion}

The inhibition of small-intestinal carbohydrate digestive enzymes is a feasible means of suppressing abnormal postprandial changes in blood glucose concentrations and minimising the progression of T2D. This has been done using acarbose, which is a $\alpha$-glucosidase inhibitor ${ }^{(16)}$.

L-Arabinose has been suggested to be a potent sucrase inhibitor and, recently, a maltase inhibitor, as an in vitro study using L-arabinose demonstrated a non-competitive inhibition of sucrase $^{(12)}$ and a yet-to-be-published study (I Krog-Mikkelsen, S Petersen, K Halschou-Jensen, O Hels, I Tetens, JJ Holst, JR Andersen and K Bukhave, unpublished results) has demonstrated a similar inhibition of maltase. The inhibition of maltase is not as pronounced as that of sucrose, but the intake of starch is relatively higher than that of sucrose, which leads to a potentially new perspective regarding L-arabinose in relation to lowering postprandial blood glucose concentrations and insulin secretion.

Studies 1 and 2 were performed in healthy young men in accordance with ethical guidelines on the use of patients as subjects in trials without a documented effect in healthy human subjects.

The test meals were designed to resemble a normal breakfast meal with bread, muffin, butter, jam and tea and to contain both sucrose and starch from wheat flour or only starch from wheat flour to investigate the effects of $\mathrm{L}$-arabinose on both sucrase and maltase.

Juntunen et $a l .{ }^{(17)}$ showed that a meal containing wheat bread with $50 \mathrm{~g}$ of available carbohydrate increases plasma glucose concentrations up to $7 \mathrm{mmol} / \mathrm{l}$ and then restores them to basal levels within $3 \mathrm{~h}$. This generates desirable conditions for measuring postprandial blood responses and the meals contained a minimum of $50 \mathrm{~g}$ of carbohydrate from sugars and wheat flour. Serum $C$ peptide was used as a measure of $\beta$-cell function and thereby insulin secretion ${ }^{(18)}$.

L-Arabinose was added on a weight $\%$ basis in relation to sucrose and starch contents and the concentrations -5 and 
$10 \%$ L-arabinose - were based on a previous study with L-arabinose (maximum 8\%) added to a sucrose drink ${ }^{(12)}$.

To determine the amount of L-arabinose included in the meals, the buns and muffins were analysed for L-arabinose content after baking. This analysis showed 90 and $70 \%$ recovery of L-arabinose in the buns and muffins, respectively. A $100 \%$ recovery was expected and further analyses were carried out. Analysis of the dough and extraction of fat revealed a similar recovery. It was assumed that all L-arabinose that was added was available in the meals and that the low recovery of L-arabinose was due to the method used for measuring the L-arabinose content.

The main findings from study 1 were that there were no differences in the $C_{\max }$ or $T_{\max }$ values of plasma glucose, serum insulin and serum C-peptide after consumption of meal A or meal B (Fig. 1)

A few significant findings were recorded after consumption of test meal B, i.e. the iAUC values of insulin and C-peptide were higher after consumption of meal B with $0 \% \mathrm{~L}$-arabinose than after consumption of meal B with 10\% L-arabinose $(P=0 \cdot 022)$. These results conflicted with our expectation.

This could be due to delayed gastric emptying after consumption of the solid food. This could affect the presentation of L-arabinose, disaccharides and starch to the epithelium of the small intestine. In addition, the concentration of sucrose in meal A could provide an explanation, as the amount of sucrose used in the drinking study was three times greater than that in meal $\mathrm{A}$.

To investigate some of the limitations mentioned herein, an indirect measurement of gastric emptying was performed in study 2 .

In study 2, starch from wheat flour was used in the mixed meals. Although the inhibiting effect on maltase seems to be less pronounced than that on sucrase, it led us to investigate the interaction of L-arabinose with meal B containing starch, as starch is the main glucose-providing carbohydrate.

In addition, no liquid version of starch was tested, and based on the questions about gastric emptying rate (GER) and the probability of dilution of the gastric volume, the dose of L-arabinose added to starch was increased to $20 \%$ by weight. Meal $\mathrm{B}$ was designed in three different textures: a liquid maltose drink; a semi-solid meal B; a solid meal B, all supplemented with $20 \%$ L-arabinose.

The main findings from study 2 were that there were no differences in the $C_{\max }, T_{\max }$ or iAUC values of plasma glucose, serum insulin and C-peptide after consumption of the solid meal, semi-solid meal or liquid meal containing 0 and $20 \%$ arabinose (Fig. 2)

As has been mentioned above, the GER is an important factor in digestion and studies have shown that the GER is affected by the composition of food and the transition time for solid foods is greater than that for a liquid meal ${ }^{(19)}$ and, accordingly, absorption is slower.

There were no differences in the AUC or $C_{\max }$ values of paracetamol in the plasma after consumption of the solid, semi-solid or liquid meal.

However, the $T_{\max }$ was different $(P<0.0001)$ for the three meals. The $T_{\max }$ for the solid meal was $35 \mathrm{~min}$ compared
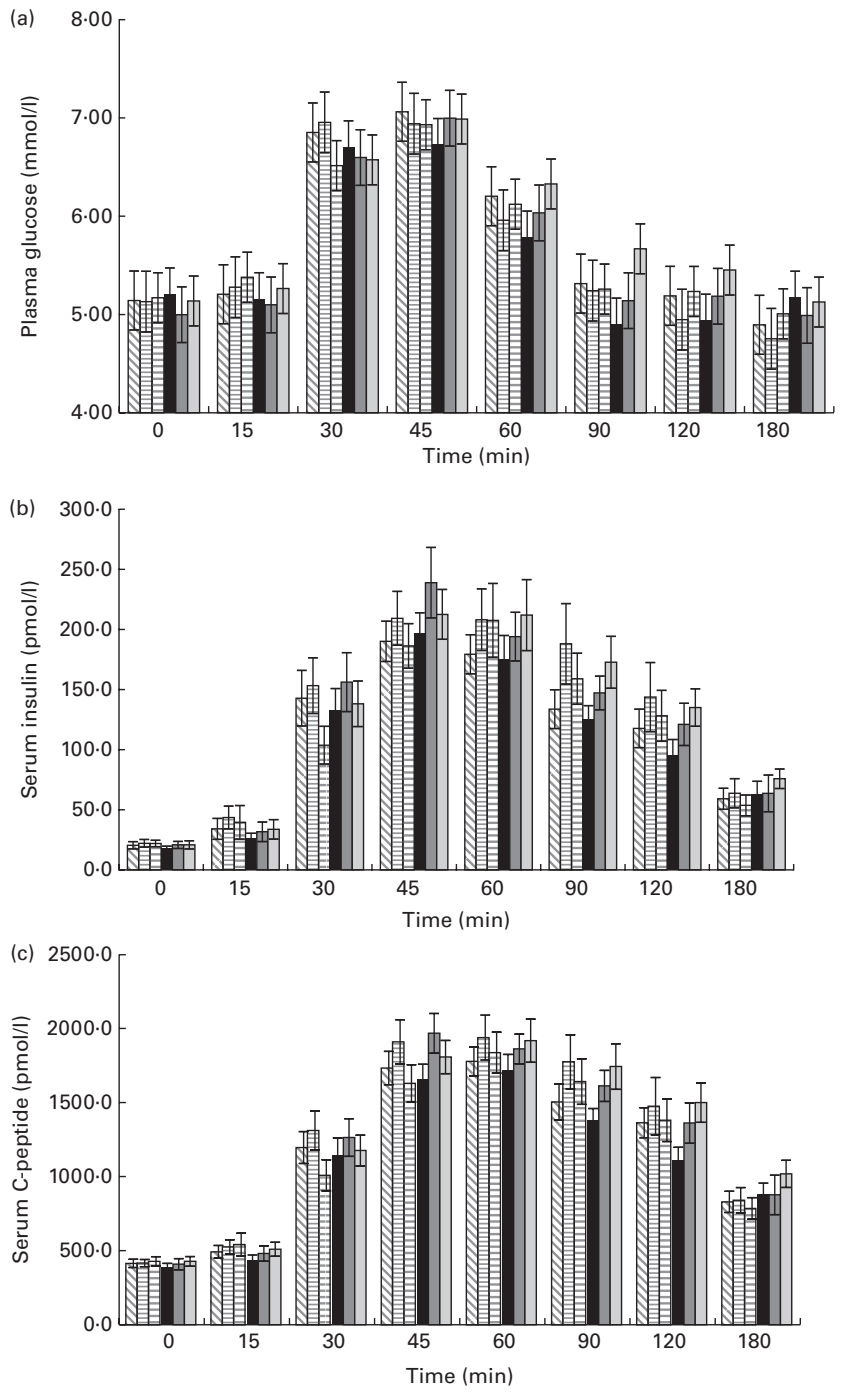

Fig. 1. Mean plasma and serum concentrations of (a) glucose, (b) insulin and (c) C-peptide in seventeen normal men after consumption of meal A containing sucrose and starch from wheat flour supplemented with 0, 5 and $10 \%$ L-arabinose by weight, butter, raspberry jam supplemented with arabinose and tea and meal $\mathrm{B}$ consisting of two buns containing starch from wheat flour supplemented with 0, 5 and $10 \%$ L-arabinose by weight, butter, cheese and tea. No significant changes were observed in peak plasma concentrations, time to reach peak plasma concentrations or incremental AUC (iAUC) after consumption of meal $A$. No significant changes were observed in peak plasma concentrations and time to reach peak plasma concentrations after consumption of meal B. The iAUC for meal B with $10 \%$ arabinose was $8 \%$ greater than that for meal $B$ with $0 \%$ arabinose $(P=0.022)$. Values are means, with their standard errors represented by vertical bars. Meal $A$ : $\square$, control; $\boxminus, 5 \%$;, , $10 \%$. Meal B: $\square$, control; $\square, 5 \%$; $\square, 10 \%$.

with $88 \mathrm{~min}$ for the semi-solid meal $(P=0.08)$ and $118 \mathrm{~min}$ for the liquid meal $(P<0 \cdot 0001)$. Furthermore, the slope, which describes the GER, was similar for the liquid and semi-solid meals (0.008 and 0.0046), whereas the slope for the solid meal was negative $(-0.006)$. These findings were rather contradictory in the sense that the observed difference in the GER was due to the solid meal having a greater $T_{\max }$ value and a negative GER compared with the semi-solid and liquid meals, both of which had lower $T_{\max }$ values. These contradictory findings could be due to the method used to measure paracetamol concentrations. 

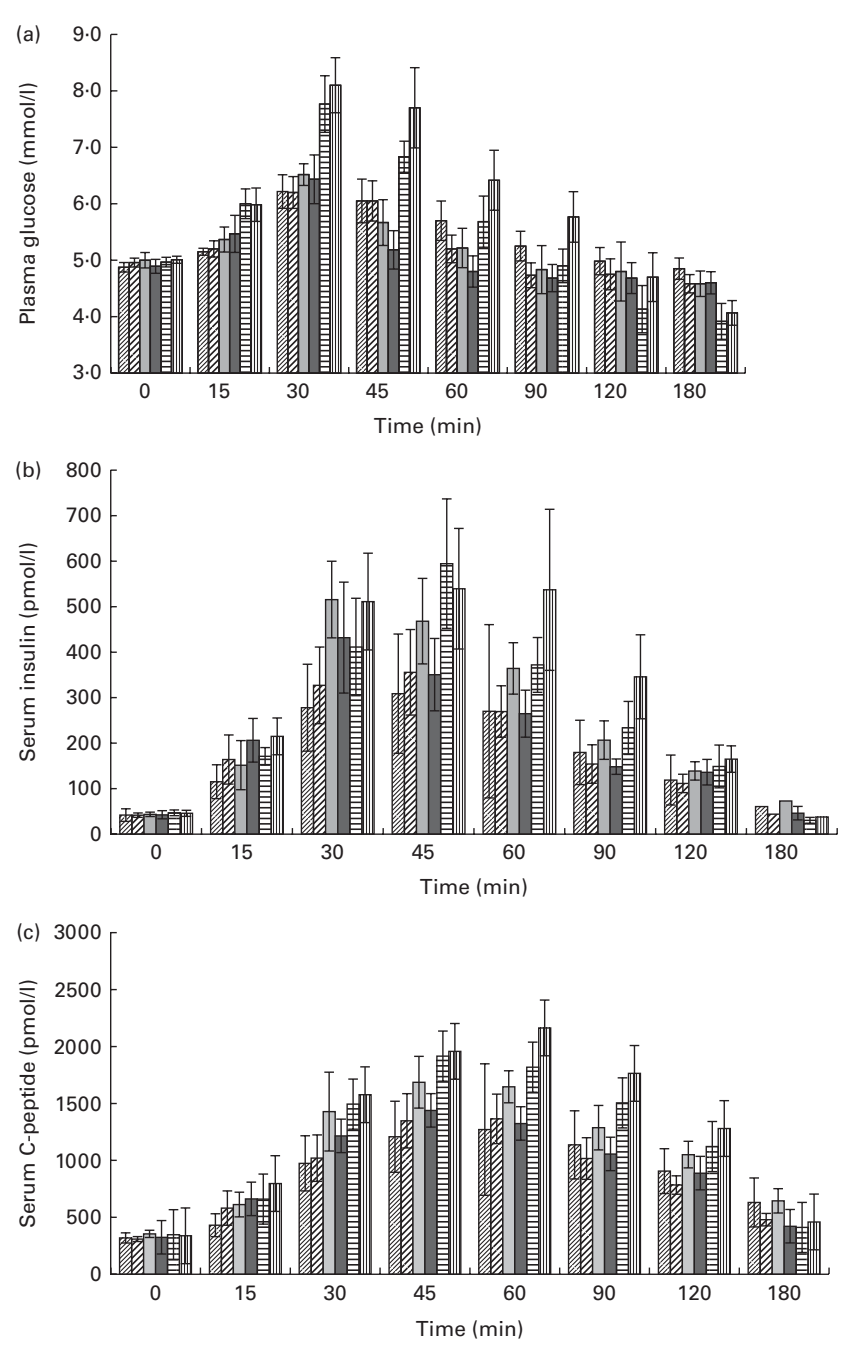

Fig. 2. (a) Mean plasma and serum concentrations of glucose, insulin and C-peptide in six normal men after consumption of solid meal B consisting of two buns containing starch from wheat flour supplemented with 0 or $20 \%$ L-arabinose by weight, butter, cheese and tea. No significant changes were observed in peak plasma concentrations, time to reach peak plasma concentrations or incremental AUC (iAUC). (b) Mean plasma and serum concentrations of glucose, insulin and C-peptide in six normal men after consumption of semi-solid meal $B$ consisting of two buns with starch supplemented with 0 and $20 \%$ L-arabinose by weight, butter, cheese and tea. No significant changes were observed in peak plasma concentrations, time to reach peak plasma concentrations or iAUC. (c) Mean plasma and serum concentrations of glucose, insulin and C-peptide in six normal men after ingestion of a maltose drink with $75 \mathrm{~g}$ of maltose in $300 \mathrm{ml}$ water with 0 and $20 \%$ L-arabinose by weight. No significant changes were observed in peak plasma concentrations, time to reach peak plasma concentrations or iAUC. Values are means, with their standard errors represented by vertical

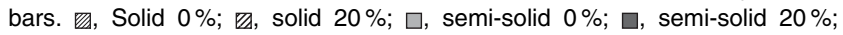
目, liquid $0 \%$; m, liquid $20 \%$.

The results of serum paracetamol assay performed in study 2 indicate that the GER is greater for the liquid meal than for the semi-liquid meal, which confirms the assumption that the GER may be a factor that affects the results recorded after consumption of the sucrose meal in study 1 .

At present, various methods are available to assess gastric emptying, of which scintigraphy is the best validated method and considered the gold standard ${ }^{(20,21)}$. However, scintigraphic measurements require medical equipment and radiation exposure. Therefore, a more simple and easy-toperform method is of interest for gastric emptying studies. Willems et al. ${ }^{(13)}$ found that the paracetamol method generally correlates well with scintigraphy of liquid-phase gastric emptying. Orally administrated paracetamol is poorly absorbed in the stomach, but rapidly absorbed from the small intestine. As gastric emptying is a rate-limiting step, it is believed that the rate of appearance of paracetamol in the blood reflects the $\mathrm{GER}^{(22)}$

One of the most important conditions for the measurement of gastric emptying is that the marker should be emptied at the same rate as the compound in question. Whether this is true for the solid and semi-solid meals used in the present study is questionable. The subjects were instructed to mix paracetamol dissolved in water with the test meal during consumption. Whether paracetamol was mixed efficiently with the meal is questionable and may be one of the reasons for the findings. In other studies using this method, paracetamol was baked into the test products ${ }^{(16,17)}$. The results of study 2 raise questions about the method and its feasibility when using a solid meal as the test meal.

In conclusion, the results of studies 1 and 2 showed that L-arabinose had the greatest sucrase-inhibiting effect and the effect was most promising when it was mixed with sucrosecontaining drinks than with starch-containing drinks. Furthermore, the inhibiting effects were not observed when L-arabinose was added to solid mixed meals containing sucrose and starch from wheat flour. It could have been interesting to have recruited subjects with insulin resistance, as they have a much higher risk of developing T2D.

\section{Acknowledgements}

The authors thank Mona Pedersen, Elin Skytte and Kristina Møller for expert technical assistance and the study subjects for their willing participation.

Nordic Sugar (Copenhagen, Denmark) funded the study, but had no influence on the protocols, design, calculations or decision to publish the manuscript. Nordic Sugar A/S (Copenhagen, Denmark) supported PhD student K. H.-J., but had no influence on the protocols, design, calculations or decision to publish the manuscript.

The authors' contributions are as follows: K. H.-J., J. R. A., K. B., S. N. and K. E. B. K. contributed to the study design and protocol; K. H.-J. collected the data; K. H.-J., J. R. A., K. B. and K. E. B. K. analysed the data; K. H.-J., J. R. A., K. B., S. N. and K. E. B. K. wrote the manuscript; K. H.-J., J. R. A., K. B., S. N. and K. E. B. K. approved the final version of the manuscript.

None of the authors has any conflicts of interest to declare.

\section{References}

1. Lorenzo CM, Wagenknecht LED, D'Agostino RBJ, et al (2010) Insulin resistance, [beta]-cell dysfunction, and conversion to type 2 diabetes in a multiethnic population: 
The Insulin Resistance Atherosclerosis Study. Diabetes Care 33, 67-72.

2. DeFronzo RA (2010) Insulin resistance, lipotoxicity, type 2 diabetes and atherosclerosis: the missing links. The Claude Bernard Lecture 2009. Diabetologia 53, 1270-1287.

3. DECODE Study Group, on behalf of the European Diabetes Epidemiology Group (2001) Glucose tolerance and cardiovascular mortality: comparison of fasting and 2-hour diagnostic criteria. Arch Intern Med 161, 397-405.

4. Sorkin JDM, Muller DCM, Fleg JLM, et al. (2005) The relation of fasting and 2-h postchallenge plasma glucose concentrations to mortality: data from the Baltimore longitudinal study of aging with a critical review of the literature. Diabetes Care 28, 2626-2232.

5. Ceriello A, Colagiuri S, Gerich J, et al. (2008) Guideline for management of postmeal glucose. Nutr Metab Cardiovasc Dis 18, 17-33.

6. Pedersen AN, Fagt S, Groth MV, et al. (2010) Danskernes kostvaner 2003-2008 (Dietary habits in Denmark 2003-2008). Søborg: DTU Fødevareinstituttet.

7. Tucci SA, Boyland EJ \& Halford JC (2010) The role of lipid and carbohydrate digestive enzyme inhibitors in the management of obesity: a review of current and emerging therapeutic agents. Diabetes Metab Syndr Obes 3, 125-143.

8. McDougall GJ \& Stewart D (2005) The inhibitory effects of berry polyphenols on digestive enzymes. Biofactors 23, 189-195.

9. Seri K, Sanai K, Matsuo N, et al. (1996) L-Arabinose selectively inhibits intestinal sucrase in an uncompetitive manner and suppresses glycemic response after sucrose ingestion in animals. Metabolism 45, 1368-1374.

10. Osaki S, Kimura T, Sugimoto T, et al. (2001) L-Arabinose feeding prevents increases due to dietary sucrose in lipogenic enzymes and triacylglycerol levels in rats. J Nutr 131, 796-799.

11. Inoue S, Sanai K \& Seri K (2000) Effect of L-arabinose on blood glucose level after ingestion of sucrose-containing food in human. J Jpn Soc Nutr Food Sci 53, 243-247.
12. Krog-Mikkelsen I, Hels O, Tetens I, et al. (2011) The effects of L-arabinose on intestinal sucrase activity: doseresponse studies in vitro and in humans. Am J Clin Nutr 94, $472-478$.

13. Willems M, Quartero AO \& Numans ME (2001) How useful is paracetamol absorption as a marker of gastric emptying? A systematic literature study. Dig Dis Sci $\mathbf{4 6}$, 2256-2262.

14. Knudsen KEB (1997) Carbohydrate and lignin contents of plant materials used in animal feeding. Anim Feed Sci Technol 67, 319-338.

15. Connors KA \& Pandit NK (1978) $N$-Methylimidazole as a catalyst for analytical acetylations of hydroxy compounds. Anal Chem 50, 1542-1545.

16. Najjar AM, Parsons PM, Duncan AM, et al. (2009) The acute impact of ingestion of breads of varying composition on blood glucose, insulin and incretins following first and second meals. Br J Nutr 101, 391-398.

17. Juntunen KS, Niskanen LK, Liukkonen KH, et al. (2002) Postprandial glucose, insulin, and incretin responses to grain products in healthy subjects. Am J Clin Nutr $\mathbf{7 5}$, $254-262$.

18. Horwitz DL, Starr JI, Mako ME, et al. (1975) Proinsulin, insulin, and C-peptide concentrations in human portal and peripheral blood. J Clin Invest 55, 1278-1283.

19. Maes BD, Hiele MI, Geypens BJ, et al. (1998) Gastric emptying of the liquid, solid and oil phase of a meal in normal volunteers and patients with Billroth II gastrojejunostomy. Eur J Clin Invest 28, 197-204.

20. Parkman HP, Harris AD, Krevsky B, et al. (1995) Gastroduodenal motility and dysmotility - an update on techniques available for evaluation. Am J Gastroenterol 90, 869-892.

21. Smout A, Horowitz M \& Armstrong D (1994) Methods to study gastric-emptying. Dig Dis Sci 39, S130-S132.

22. Heading RC, Nimmo J, Prescott LF, et al. (1973) Dependence of paracetamol absorption on rate of gastric emptying. Br J Pharmacol 47, 415-421. 